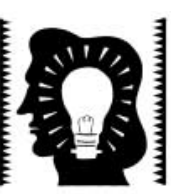

special article

Psychiatric Bulletin (2009), 33, 219-225. doi: 10.1192/pb.bp.108.023184

\begin{abstract}
PAUL ST JOHN-SMITH, DANIEL MCQUEEN, ALBERT MICHAEL，GEORGE IKKOS,
CHESS DENMAN, MICHAEL MAIER, ROBERT TOBIANSKY,

HEMACHANDRAN PATHMANANDAM, TEIFON DAVIES, V. SUNIL BABU, OMANA THACHIL, FURHAN IQBAL AND RANGA RAO
\end{abstract}

\title{
The trouble with NHS psychiatry in England
}

\author{
SUMMARY \\ In 'Wake-up call for British psych- \\ iatry' Craddock et al explained \\ how recent attempts to improve \\ psychosocial care for people with \\ mental illness focus on non-specific \\ psychosocial support. This has been \\ at the expense of proper diagnostic \\ assessment and prescription of \\ treatment by psychiatrists aimed at
}

\author{
treatment of specific disorders and \\ recovery. They describe a creeping \\ devaluation of psychiatry which is \\ caricatured as narrow, biological, \\ reductionist, oppressive, discrimin- \\ atory and stigmatising. Some trusts \\ have implemented 'New Ways of \\ Working for Psychiatrists' in a \\ way that undermines the central \\ importance of psychiatrists in mental
}

healthcare. Consequently, patients may be treated in secondary care without ever being seen by a psychiatrist. We consider a number of different changes that have interacted in unforeseen ways, with unintended adverse consequences for psychiatric services in England. We aim to continue the debate here.

\section{Reforms}

Since the 1990s, the National Health Service (NHS) has been in a state of perpetual reform. Emphasis has shifted from meeting the needs of patients as assessed by clinicians to achieving centrally set targets as in the National Service Framework for Mental Health. ${ }^{1}$ Business models administered by an expanded NHS management ${ }^{2}$ and a specific focus on private sector providers ${ }^{3}$ have been introduced. Each reform has moved mental healthcare away from the priorities of psychiatrists, such as the clinical perspective and providing a reactive service to the most unwell, to those of politicians. Instead of openly debating the rationing and funding of healthcare, political decisions about funding are reformulated as local service efficiency and resource management problems to be resolved by further political reforms. Services are changed without evidence that the changes improve care. Reformers talk about 'prevention' to justify introducing new services, initiatives and strategies, without providing adequate evidence that they prevent anything. Unfortunately, to establish these new services, existing services that aim to satisfy clinical needs are cut. The introduction of assertive outreach teams was one such initiative. $^{4}$

\section{Audit}

The new NHS market economy requires a common currency for comparing wholly different services. New 'measures' are created to facilitate auditing but these often distort clinical practice and destabilise services. ${ }^{5}$ Attempts to render organisations auditable result in 'decoupling', whereby the auditable outcomes become separated from the actual work of the organisation, which then produces irrelevant figures for central consumption rather than as part of an audit cycle aimed at learning and improving services. Another effect is 'colonisation' whereby the audit world spills over into the clinical and provides a dominant reference point for organisational activity, so that things are done because they are audited rather than because they are beneficial or necessary. In higher education the introduction of audit to allocate resources had a 'fatal' impact on research culture. $^{6}$ Similar effects are appearing in the NHS, for example Goodhart's law ${ }^{7}$ - the paradox that when a surrogate measure is made a target for conducting policy, it loses the information content that would qualify it to play such a role, making the measures of doubtful value even to those who require them. The government recognises that top-down targets stop the police from policing but does not recognise a similar process in healthcare. ${ }^{8}$

\section{Changes in medical regulation}

Politicians use medical scandals to limit the professional independence of doctors and to bring them more directly under state control. 'The individual orientation that doctors are trained for does not fit with the demands of current healthcare systems'.,10 Renegotiating the compact (sic) between the medical profession and 
society ${ }^{11}$ and revising medical and psychiatric professionalism ${ }^{12,13}$ are overdue. We welcome the appropriate development of accountability that comes with medical professionalism; indeed this is why we believe professionalism is important. However, excessive and intrusive regulation wastes resources, deflects from clinical work, stifles creativity, and displaces time-tested methods of professional self-regulation. ${ }^{14}$ This is not unique to psychiatry, but psychiatrists are more vulnerable to this because psychiatric practice involves risk taking and managing uncertainty.

\section{Spin}

The new rhetoric of healthcare seeks to achieve hegemony by the appropriation of language in a way that makes opposition or even debate, however principled and evidence-based, sound narrow or ridiculous. How can anyone question or debate 'politically correct' catchphrases like Vision, Empowerment, Recovery, Best Practice, Clinical Excellence, High Quality, Accelerating Change, Personalised Services, Choice, Partnership, and Continuous Improvement?

\section{New Ways of Working}

New Ways of Working was a practical response to the shortage of consultant psychiatrists and the demoralisation of psychiatrists caused by excessive workload in the late 1990s. ${ }^{15,16}$ In 2004, a national working group with high-level representation from many interested groups reviewed the roles and responsibilities of psychiatrists; this included the Royal College of Psychiatrists. The group suggested that consultant psychiatrists should move from their traditional roles of taking referrals, diagnosing, treating, allocating and overseeing clinical work, providing continuity of care over time and across settings and holding clinical responsibility, to becoming 'truly consultative with multidisciplinary teams taking responsibility for patient care.' The concept of distributed responsibility within multidisciplinary teams was introduced, which meant that every team member was seen as accountable for what they did. ${ }^{17}$ The College agreed these changes after consultation with its membership. ${ }^{18}$ This was intended not as a way of cutting medical staff, but a way of using consultants and all other members of the multidisciplinary team to do what they do best. Also planned was a training package that would allow nonmedical members of each team to assume their new extended roles. ${ }^{19}$ If well implemented, this could improve services for patients and job satisfaction for all staff. However, New Ways of Working can and has become shorthand in trust boards for cutting the numbers of medical staff and for reducing the psychiatric orientation of the service. This has led to the removal of consultant psychiatrists from assessment, diagnosis and treatment planning, but non-medical staff have often not been able to take over this role because they are not adequately trained. This has resulted in services that are not capable of offering psychiatric assessments and treatment. ${ }^{20}$ In our experience this results, at times, in clinically unacceptable low standards.

\section{Functional teams}

Functional teams have been introduced alongside New Ways of Working. This meant splitting sector-based psychiatry teams into community mental health teams (CMHTs), primary care mental health teams, crisis resolution teams, home treatment teams, recovery teams, inpatient teams, complex enhanced care programme approach teams, assertive outreach teams, early intervention teams, etc. This means that patients may see three or four consultants during a single episode of acute illness. There are some advantages in this. Specialist teams are more focused and can be more efficient, and the implementation of specialist in-patient teams has greatly improved in-patient care. The creation of home treatment teams, which operate round the clock, has significantly reduced bed usage and improved the capacity to provide home treatment to those who are acutely ill. However, this has often reduced community care for those with the more complex psychiatric disorders because these changes were implemented without expanding overall resources and because staff recruited to new teams came from the same recruitment pool and has not been replaced. This will get worse with the national implementation of the Improving Access to Psychological Therapies programme, ${ }^{21}$ because their staff also will come from the same pool. The introduction of functional teams fragmented services and created new problems.

- There are many boundary disputes about who should look after individual patients, which distracts from patient care.

- There are communication problems between teams most serious untoward incident inquiries highlight communication difficulties as a major factor in suicides and homicides.

- Patients miss long-term relationships with their doctors or nurses on whom they rely at times of difficulty; such relationships have important effects on outcome even in drug treatments. ${ }^{22}$

- Dealing with many different professionals along complex care pathways through a fragmented functional service activates some patients' attachment difficulties and may cause iatrogenic harm. ${ }^{23}$

Many of these problems can be overcome; there are examples of functional services that work well and provide high-quality and safe services which are more effective than the sector-based services that they have replaced. However, this requires careful planning and effective management. Unfortunately, this has not always happened, particularly when CMHTs become depleted of staff. On balance, our experience leads us to believe the haphazard implementation of functional teams has resulted in poorer services. 


\section{Changes in training}

Along with the fragmentation of care, a similar fragmentation of knowledge has come in the form of competency-based training. Competency in a profession is of paramount importance but the spotlight on competency-based assessments takes the focus away from the competencies that are difficult to measure and that allow an understanding of the patient's narrative. This is akin to the age-old question, 'Is medicine art or science?' Psychiatry is clearly both. It is important that we do not end up measuring things purely because they are measurable and ignoring those that are difficult to measure. Complex professional skills and qualities that take years of training and apprenticeship to master must not be reduced to isolated competencies that become part of a box-ticking exercise. Learning to fill in forms is not sufficient professional education. Sennett explained that craftsmanship requires interplay between tacit knowledge and self-conscious awareness: 'When an institution like the NHS, in churning reform, doesn't allow the tacit anchor to develop, then the motor of judgement stalls. People have no experience to judge, just a set of abstract propositions about good-quality work.' ${ }^{24}$ This is even more acute for non-medical colleagues who may be expected to perform new tasks outside of their core professional role after minimal training.

\section{The new reductionism}

Reductionist developments have impoverished the mental health services. Providing high-quality psychiatric care is reduced to meeting targets; professionalism is reduced to competences; diagnostic assessment is reduced to assessing needs and risk; clinician-patient relationships are reduced to an assembly line model where functional teams provide 'client-centred' but fragmented and impersonal care. The current emphasis on 'mental health' rather than psychiatric illness, 'health centres' rather than hospitals or clinics and 'recovery' rather than treatments represent 'magical thinking' in attempts to deny the existence of 'madness'. ${ }^{25}$ These manoeuvres also help to tidy away the suffering and emotional pain of the mentally ill person.

Comparing the current state of mental healthcare with the government rhetoric about services at times recalls the Orwellian satire ${ }^{26}$ on the command economy of the former Soviet Union, where the Party proclaims ever more grandiose plans, exhortations, targets and selfcongratulations; everyone knows, and doesn't know at the same time that the targets are absurd and often irrelevant, their results are unreliable and the goods are, all too often, shoddy. Work then becomes a game of survival to produce figures to fulfil the impossible targets. For example, the 'NHS strategic plan' or Darzi report ${ }^{27}$ refers to 'change fatigue' and states 'that NHS staff is tired of upheaval - when change is driven top down,' yet it proposes another 40 changes while promising 'no new national targets'.

Incredibly, there has been no systematic sustained data collection by the Department of Health to monitor the impact of the 'market-style' NHS reforms ${ }^{28}$ following the 'NHS plan'. ${ }^{29}$ Evidence that commissioners add value or are cost-effective is not demonstrated.

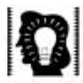

special article

\section{What patients want}

When asked about aspects of care, patients rank their contacts with doctors as among the most important issues (Box 1).

Harm done through managerial and political wasted resources should be given equal status to the harm done by side-effects of drugs and rogue doctors. Reorganisations, structural changes, new systems of audit, analysis, and revalidation, all should be subject to the same level of testing and proof before they are introduced as applies currently to medical treatments. We recognise that most middle-grade and senior managers appreciate the fallacy of what is going on, but they are under immense pressure from the centre to meet the targets, and under threat of not getting foundation status or losing funding.

Given how bad things actually are, it is surprising that the profession seems to have had difficulty in speaking up for patients and for psychiatric care. Perhaps

Box 1. Selected results from the 2006 in-patients importance study ${ }^{30}$

Rankings in importance from 1 (most important) to 82 (least important):

1 The doctors know enough about my medical history and treatment.

2 The doctors can answer questions about my condition and treatment in a way that I can understand.

3 I have confidence and trust in the hospital staff that treats me.

10 The doctors and nurses are open with me about my treatment or condition.

12 I am told how I should take my medicines.

18 The doctors and nurses are reassuring.

24 The doctors and nurses work well together.

25 I am told which doctor is in overall charge of my care.

27 I am told who to contact if I am worried about my condition after I leave the hospital.

40 The staff dealing with my care introduce themselves to me.

59 I receive copies of letters between the hospital doctors and my family doctor (GP).

73 I am told how to make a complaint about the care I receive.

74 I have a choice of admission dates.

75 I receive printed information about the hospital before admission.

76 I have a choice about which hospital I am admitted to.

77 I receive help to eat my meals, at the time I need it.

78 The hospital provides facilities that allow me to practise my religious beliefs.

79 A translator or interpreter is provided by the hospital.

80 I have enough information about different hospitals so I can make a choice.

81 I have access to food when I am hungry (not just at mealtimes).

82 I am not bothered by noise during the day. 
it is fear of being envied that prompts psychiatrists to deny their own training, skills and authority, ${ }^{31}$ or perhaps it is because of change fatigue and the conviction that

special article nothing they can do would affect the outcome (learnt helplessness). Stung by these criticisms (Box 2) and at times failing to find immediate responses to them, psychiatrists have either retreated into the safety of clinical practice ('I don't do politics') or embraced changes which sober reflection would have revealed are not in the best interests of patients.

\section{The importance of multiple perspectives}

Psychiatric illnesses and their treatments are complex. A range of professional skills, perspectives and personal

\section{Box 2. Criticisms and caricatures levelled at psychiatry $^{32,33}$}

\section{Comment}

These criticisms misinform managers, politicians and commissioners, who then assume that psychiatrists are of little or no value and that anyone can be substituted with minimal training to assess and treat patients.

The social constructionists: maintain that psychiatric diagnosis and biological psychiatric research are irrelevant or social constructs no more valid than any other; disability and distress should be explained and tackled exclusively in social terms; psychiatric diagnosis is a form of social control.

Psychiatric expertise: psychiatrists are considered elitist, privileged, undemocratic and distant. They have no special training or knowledge.

The integrity of psychiatrists: some caricature all psychiatric clinicians and researchers as corrupt 'pill pushers' in the pockets of the pharmaceutical industry. ${ }^{34}$

Selective abstraction: includes exaggerating the harms of psychiatric treatment and ignoring the risks of undertreatment.

Economic irrelevance: depression and anxiety are the biggest mental health problem in society and these can be treated most cost-effectively in independent psychological treatment centres. ${ }^{33,34}$ Hence, the economic argument goes, put money where it makes most difference to the economy.

Human rights: some champions of personal freedom regard compulsory treatment of the mentally ill as violation of human rights, while ignoring the inhumanity of the alternative that is using the criminal justice system. The converse paradigm is the panic response to the risk posed by releasing 'dangerous' psychiatric patients from hospitals.

The scientific basis: some allege that science and psychiatry are no more than one of a number of alternative ideologies or belief systems with equal status. These alternative views are only felt to need personal confirmation through individual feeling, observation, view, opinion or 'one-off' experience. Conversely, the broad-based biopsychosocial synthesis in psychiatry is required to present $100 \%$ perfect scientific evidence before it is accepted.

The guideline culture: the importance of clinical experience, training, wisdom and judgement is minimised; psychiatric practice is reduced to the application of oversimplified algorithms and guidelines that can ostensibly be understood and applied equally well by any generic mental health worker, educated lay person, bureaucrat, manager or commissioner. Make everything as simple as possible, but not simpler. ${ }^{35}$

qualities are required to provide a high-quality psychiatric service. These professional roles and personal qualities cannot be met in one individual or covered by one's professional training. Assessments by non-psychiatrist members of the team are vital to providing a broad psychosocial perspective. We recognise that in some circumstances some non-psychiatric colleagues can provide better and more comprehensive assessments than some psychiatrists. Our own experience is that assessments are enriched by jointly working with colleagues from other disciplines. True multidisciplinary teams are essential. These should have a differentiated structure with distinct roles of authority and responsibility matched to the particular skills and abilities of the individuals. Forcing anyone to perform tasks outside of their professional remit and for which they are not trained, while denying them the opportunity to perform the tasks for which they are trained is a potentially harmful waste of professional resources. Multidisciplinary teams need clinical leadership. Properly trained consultant psychiatrists are often, though not invariably, the best professionals to do this. Psychiatrists need to be trained in clinical leadership and in this role they also need to engage in the tasks of rationing care, which is unavoidable in the NHS.

The following scenarios (case vignettes 1-4) based on composites of real experiences illustrate many of these points. We appreciate that everyone makes mistakes. However, mistakes are much more likely when people are required to do tasks that they are not trained to do.

\section{Case vignette 1}

A woman was referred by her general practitioner (GP) for an urgent psychiatric opinion. Her distraught husband took her to the casualty department and a liaison psychiatric worker assessed her. She was thin, withdrawn, dehydrated and was not eating. The worker diagnosed anorexia nervosa and referred her to the area eating disorder unit; she was placed on the 3-4 weeks' waiting list. As time went on her condition deteriorated. The GP then demanded an assessment by the psychiatrist. The psychiatrist recognised that the patient had presented originally with a severe psychotic depression. The psychiatrist had to rescue the patient from the initial incorrect diagnosis and disastrous care plan. The history, symptoms, mental state, diagnosis, treatment and prognosis of severe depression is radically different to that of anorexia nervosa. This diagnostic error was recognised only by the psychiatrist who then had to battle with a member of the local crisis team to secure an admission to a psychiatric ward. The patient made a complete recovery with a combination of pharmacological and psychological treatments and electroconvulsive therapy (ECT).

How do we know this was the right thing to do? There were no blood tests to prove the patient had depression. The differential diagnoses of individuals not eating do include anorexia nervosa of course, but other factors, not recognised initially, suggested another diagnosis. The National Institute for Health and Clinical Excellence (NICE) guidelines would not have helped. Possible reasons for not eating can also include: medical illness (e.g. malignancy or uraemia), paranoid psychosis, dementia, as well 
as the severe psychotic depression, and indeed family issues, and combinations of the above.

\section{COMMENT}

Diagnosis in mental health can be far from straightforward and requires a broad range of medical and psychiatric skills and knowledge; misdiagnosis can be fatal. Many of our non-psychiatrist colleagues are uncomfortable and feel dangerously exposed when asked to perform assessments outside of their core professional training. In our experience they share our view that it is a false economy to bypass assessment by psychiatrists.

\section{Case vignette 2}

A GP requested an urgent assessment for compulsory admission of a middle-aged woman whom he thought was depressed, psychotic, suicidal and in need of ECT.

A psychiatrist carried out a comprehensive assessment including the current symptoms, medical, psychiatric, family and treatment history, current circumstances, and physical and mental state examination, leading to a diagnosis, aetiology, a management plan and prognosis. The psychiatrist explained that the patient had an agitated depression that had not responded to increasing doses of fluoxetine, which paradoxically had probably added to the agitation. Hence, the best option was to substitute fluoxetine with a sedative tricyclic antidepressant. She did not require admission to hospital, voluntary or compulsory, nor ECT. The psychiatrist discussed the possible benefits and risks of changing medication, and whether her husband could cope. Also, a care plan including daily monitoring of progress was discussed with the patient, her husband and the home treatment team. After a few days of cross-tapering, the patient rapidly improved on the new medication.

The initial response of the GP who had made the referral was '[If only] I could have done that'.

\section{COMMENT}

Psychiatrists may spend a long time assessing patients and checking risks carefully, using complex professional judgement, born of years of training. All too often this professionalism, expertise and judgement are not valued or worse still, seen as trivial. If one reduces this sophisticated clinical episode to simply a change of medication, one will regard the psychiatrist as over qualified and an expensive waste of time and resources. Our concern is that this is precisely the error made by some influential commissioning bodies, politicians, the lay public, patients, service users and relatives.

\section{Case vignette 3}

A gynaecologist sought a psychiatric opinion on a professional woman in her 50s who had become 'depressed' following a hysterectomy. Two workers from the mental health team assessed her and diagnosed her to have depression. They started treatment with a combination of counselling and cognitive-behavioural therapy. Her condition deteriorated and she attempted to throw herself from the ward window. The consultant psychiatrist was called in. On assessment he noted the incompatibility between her pre-morbid personality and functioning, and her current mental state. His first action was to inspect her temperature chart, which revealed pyrexia. He made a diagnosis of delirium secondary to post-operative infection, a condition that can be fatal. On treatment with antibiotics and lowdose antipsychotics she made a rapid and complete recovery. She did not require further psychiatric treatment.

\section{COMMENT}

A wide range of physical conditions can present with psychiatric symptoms. Diagnosis requires broad-based training in medicine and psychiatry, and years of experience. Psychiatric training uniquely and specifically focuses on diagnosis. Timely expert diagnosis can save unnecessary, wasteful and potentially harmful treatments, and save lives.

\section{Case vignette 4}

A retired executive was referred to a dementia clinic for prescription of anti-dementia drugs. Psychiatric assessment revealed subjective, but no objective memory impairment, long-standing dissatisfaction, interpersonal difficulties and a life devoid of meaningful relationships. A pervasive pattern of grandiosity, need for admiration and lack of empathy indicated narcissistic personality traits. The memory complaints were explained to the patient as a depressive pseudodementia but the depressive symptoms themselves were insufficiently severe to warrant medication. The consultation moved on to a psychotherapeutic exploration of the emptiness of his life, lack of intimate relationships and alienation from his five adult children. The patient left reflecting on the possibilities for repairing his relationships with his children. No further specific treatment was sought or recommended.

\section{COMMENT}

When performed with skill, psychiatric assessment can be therapeutic in its own right.

\section{What psychiatry is and what it should be}

Psychiatry requires expert medical practitioners to do the complex task of assessing physical and mental aspects of illnesses, and providing appropriate pharmacological and psychological treatments. ${ }^{36}$ Extensive and complex training is required to equip psychiatrists with a wide range of knowledge (medical, psychiatric and social sciences), skills (in assessment, and pharmacological and psychotherapeutic treatments) and professional attributes (ethical, managerial, maintaining appropriate relations, honesty, justice, and commitments to patient care and service quality).

The ideal psychiatrist, in Jaspers' view, is one who combines 'scientific attitudes of the sceptic with a powerful impressive personality and a profound existential faith.' He is someone with a solid foundation in medicine, the biological and behavioural sciences and is able to cope with the intellectual isolation implicit in such a critical eclecticism. The intervening years since Jaspers made his observation have not diminished the need for such a rare combination of abilities. ${ }^{37}$

What the intervening years have done is to increase dramatically the relevant knowledge base and set of skills that practitioners need to bring to the task. Thus, the capacity for change and for responding to changes in knowledge, culture, politics and health service organisation is a key attribute. For this reason psychiatrists 
should not be slow to encourage reform or weak in selfcriticism. Nor have they been. It was psychiatrists who led the moves to empty asylums. It was psychiatrists who balanced the competing biological and social theories of schizophrenia into a subtle biopsychosocial understanding of the illness. Psychiatrists strongly advocated the specialist training of all professionals in multidisciplinary teams. It has been psychiatrists who, despite doing themselves no favours with the government, have joined with others in leading the resistance to the illiberal features of the proposed changes to the Mental Health Act. It was a psychiatrist (Aaron T. Beck) who started and first developed cognitive-behavioural therapy.

\section{Conclusion and recommendations}

Psychiatry is facing multiple challenges. Endless changes and reorganisations are imposed from the centre without being piloted or assessed. New centralised models of public services administration have displaced clinical thinking and professionalism. Priorities are determined by politicians and implemented by managers with insufficient understanding of the complexities of psychiatry. Complex tasks are devolved to generic mental health workers. Increasingly, psychiatric care is provided without a proper diagnostic assessment. Instead, it is being reduced to assessing risk and needs, and providing generic psychosocial support. Services are fragmented into functional teams providing 'person-centred services' that are none the less impersonal. High-value aspects of psychiatric care, such as diagnostic assessment, tailored treatment and the therapeutic relationship, ${ }^{22}$ are not subject to targets or audited and therefore are devalued and sacrificed in the pursuit of administrative targets. Left unchallenged these will lead to further erosion of the quality of psychiatric care. Patients' needs fall into different categories - the 'one-size/plan-fits-all' approach is inappropriate, and consumer models must be modified. We recognise that all the problems we identified are not happening everywhere and/or always.

High-quality psychiatric care requires a range of professional skills: psychiatrists, psychiatric nurses, occupational therapists, psychiatric social workers, clinical psychologists, and psychotherapists, all have specific areas of professional expertise that are required, at the appropriate time, in the care of different patients.

Psychiatrists with their unique skills in diagnostic assessment and management of psychiatric illnesses are essential. High-quality psychiatric care requires more than assessment of risk and needs, and general psychosocial support. Psychosocial assessment and care is necessary but not sufficient to deliver quality psychiatric care.

Most politicians, commissioners, guideline writers or business managers, if faced with psychiatric illness in their family, would want an expert assessment by an experienced psychiatrist for their loved one, rather than assessment by a generic mental health worker using proforma tools and guidelines. We suspect that private psychiatric care will be a beneficiary of poorly implemented New Ways of Working, as those that can afford to seek
Box 3. Areas in which the Royal College of Psychiatrists should aim to influence public and political debates

1 Psychiatrists and psychiatric assessment are central to the treatment of psychiatric illness.

2 Psychiatrists and psychiatric assessment add value to mental health services.

3 The excessive use of targets is ineffective and undermines good clinical care.

4 Centrally micromanaged, guideline-driven care implemented by generic mental health workers is a false economy and is potentially harmful to patients.

5 Macro-political questions about priorities, funding and rationing in the NHS should not be misrepresented as local efficiency issues.

6 A degree of organisational stability is essential for teams to flourish.

7 Psychiatrists must be free to exercise clinical discretion (subject to regulation and scrutiny) to treat patients.

8 NICE guidelines were never intended to be rules or to cover all eventualities. Clinical care will suffer if trusts impose national guidance on psychiatrists as a set of rules.

9 Self-regulation, within the law, is a defining feature of professions. Psychiatrists should defend professional self-regulation and accountability.

10 Psychiatrists must be part of setting local priorities for psychiatric services.

11 Trainees require adequate time to gain experience before becoming consultants.

12 Medical and clinical directors, as medical professional leaders within services, should be explicitly assessed by the College on their performance in terms of whether they effectively advance the professional practice of their clinical colleagues or whether they inappropriately act to de-professionalise practice and place patients at risk of

the doctor-patient relationship and continuity of care that increasingly are available only in the private sector.

It is understood that ambiguity and uncertainty abound despite guidelines and that psychiatrists are trained specifically, and at great length and cost, to exercise clinical judgement to make difficult decisions under circumstances of great complexity.

What should be done? We welcome the Royal College of Psychiatrists' Fair Deal campaign ${ }^{38}$ that addresses many issues relating to providing high-quality services to psychiatric patients. We hope the College will begin to recognise that there can be no fair deal for patients if we as a profession do not value our own role in providing high-quality care. The College needs to recognise that NHS resources are limited and that care needs to be prioritised. Consultant psychiatrists who are clinical team leaders are ideally placed to do this working with others. We urge the College to educate further the government, clinical colleagues and the community (Box 3) on the central importance of the psychiatrist and the broad medical model ${ }^{39}$ in a comprehensive biopsychosocial assessment of patients suffering from a broad range of mental illnesses, some moderate, some severe, some acute, some long-term. 


\section{Acknowledgements}

We thank Dr David Barbenel, Professor Nick Craddock and Dr Beata Adams for their helpful contributions.

\section{Declaration of interest}

None.

\section{References}

1 Department of Health. National Service Framework for Mental Health: Modern Standards and Service Models. Department of Health, 1999 (http:// www.dh.gov.uk/en/ Publicationsandstatistics/ Publications/PublicationsPolicyAnd Guidance/DH_4009598).

2 Goldberg D. Improved investment in mental health services: value for money? BrJ Psychiatry 2008; 192: $88-91$

3 Dobson F. Exorbitant and wasteful: government plans to accelerate the privatisation of the NHS make no sense. The Guardian, 1 July 2006 (http://www.guardian.co.uk/ commentisfree/2006/jul/01/ comment. publicservices/print).

4 BurnsT, Creed F, FahyT, Thompson S, Tyrer $P$, White I. Intensive versus standard case management for severe psychotic illness: randomised trial. UK 700 Group Lancet 1999. 353: 2185-9.

5 Oyebode F. Payment by volume (not results). Invited commentary on ... Payment by results in mental health. Advan PsychiatrTreat 2007 13: 7-9.

6 Power M. The Audit Society: Rituals of Verification. Oxford University Press, 1997.

7 Goodhart CAE. Monetary relationships: a view from Threadneedle Street. In Papers in Monetary Economics, Vol. 1. Reserve Bank of Australia, 1975.

8 Home Office. Cuts in Police Red Tape and More Say for the Public on Policing [press release]. 17 July 2008 (http://press.homeoffice.gov.uk/ press-releases/Cuts-To-PoliceRed-Tape)

9 Smith R. Why are doctors so unhappy? BMJ 2001; 322 1073-4.

10 Edwards E, Kornacki MJ, Silverstein J. Unhappy doctors: what are the causes and what can be done? BM 2002; 324: 835-8.

11 Ham C, Alberti KGMM. The medical profession, the public and the (http:// Publicationsandstatistics/ Guidance/DH_4073490). of Working for Psychiatrists: Enhancing Effective, PersonCentred Services through New Ways of Working in Health, 2005 (http://www.dh. gov.uk/en/Publicationsand statistics/Publications/ DH_4122342). Department of Health, 2007 BrJ Psychiatry 2008; 193: 6-9.
21 Care Service Improvement Partnership, National Institute for Mental Health in England. Choices in Mental Health: Improving Access to Psychological Therapies (IAPT) Programme. CSIP \& NIMHE, 2006 (http://www.mhchoice. csip.org.uk/psychologicaltherapies.html).

22 KrupnickJL, Sotsky SM, Elkin I, Simmens S, Moyer J, Watkins J, et al. The role of the therapeutic alliance in psychotherapy and pharmacotherapy outcome: findings in the National Institute of Mental HealthTreatment of Depression Collaborative Research Program. J Consult Clin Psychology 1996; 64: 532-9.

23 Fonagy $\mathrm{P}$, Bateman A. Progress in the treatment of borderline personality disorder. BrJ Psychiatry 2006; 188: 1-3.

24 Sennett R. The Craftsman. Penguin Books, 2008

25 Evans M. Making room for madness in mental health: the importance of analytically-informed supervision of nurses and other mental health professionals. Psychoanal Psychother 2006; 20: 16-29.

26 Orwell G. Nineteen Eighty-Four. Penguin Books, 1970 [first published 1949].

27 Department of Health. High Quality Care forAll: NHS Next Stage Review Final Report. Department of Health, 2008 (http://www.dh.gov.uk/en/ Publicationsandstatistics/ Publications/PublicationsPolicyAnd Guidance/DH_085825).

28 Audit Commission. Is the Treatment

9 Department of Health. The NHS Plan: A Plan for Investment, A Plan for Reform. Department of Health, 2000 (http://www.dh.gov.uk/en/ Publicationsandstatistics/ Publications/PublicationsPolicyand Guidance/DH_4002960).

30 Boyd J. The 2006 In-Patients Importance Study. Picker Institute Europe, 2007 (http://www. nhssurveys.org/survey/486).

31 MainT. Some psychodynamics of large groups. InThe Large Group: Dynamics and Therapy (ed. Kreeger): 57-86. Constable, 1975.

32 Sorboro J. The trouble with psychiatry. Skeptic 2007; 13: 37-43.

33 Kingdom D, Young $A H$. Research into putative biological mechanisms of mental disorders has been of no value to clinical psychiatry. BrJ Psychiatry 2007; 191: $285-90$

34 SharkeyJ. Bedlam: Greed, Profiteering and Fraud in a Mental Health System Gone Crazy. St Martin's Press, 1994.

35 Calaprice A. The New Quotable Einstein. Princeton University Press, 2005

36 Marneros A. Psychiatry's 200th birthday. BrJ Psychiatry 2008; 193 : $1-3$.

37 Clare A. Psychiatry in Dissent. Routledge, 1980

38 Royal College of Psychiatrists. Fair Deal for Mental Health. Royal College of Psychiatrists, 2008 (http://www.rcpsych.ac.uk/ campaigns / fairdeal.aspx). Publications/PublicationsPolicyAnd

18 Department of Health. New Ways Multidisciplinary and Multiagency Contexts. Final Report 'but not the end of the story'. Department of PublicationsPolicyAndGuidance/

19 Department of Health. Creating CapableTeams Approach (CCTA): Best Practice Guidance to Support the Implementation of NewWays of Working (NWW) and New Roles.

20 Craddock N, Antebi D, Attenburrow MJ, BaileyA, Carson A, Cowen P, et al. Wake-up call for British psychiatry. Working? Progress with the NHS System Reform Programme. Audit Commission and NHS in England, 2008

39 Shah P, Mountain D. The medica model is dead - long live the medical model. BrJ Psychiatry 2007: 191: $375-7$.

Paul St John-Smith Consultant in General Adult (Assertive Outreach) and Community Psychiatry, Cranbourne Centre, Potters Bar, Daniel McQueen Specialist Registrar in Psychotherapy, Cassel Hospital, Richmond, and Psychotherapy Service, Lakeside Mental Health Unit, West Middlesex University Hospital, Isleworth, *Albert Michael Consultant in General Adult (In-Patient Care) and Community Psychiatry, Suffolk Mental Health Partnership NHS Trust, West Suffolk Hospital, Bury St Edmunds, Suffolk IP33 20Z, email: albert.michae@@smhp.nhs.uk, George Ikkos Consultant Psychiatrist (Liaison Psychiatry), Royal National Orthopaedic Hospital, Stanmore, Chess Denman Consultant Psychiatrist in Psychotherapy, Complex Cases Service, Springbank Ward, Fulbourn Hospital, Cambridge, Michael Maier Consultant Psychiatrist (Rehabilitation Psychiatry), West London Mental Health NHS Trust, Southall,

Robert Tobiansky Consultant Old Age Psychiatrist, Edgware Hospital, Hemachandran Pathmanandam Consultant Psychiatrist (Community, General Adult), Cygnet House,Ware, Teifion Davies Consultant and Senior Lecturer in Community Psychiatry, Institute of Psychiatry, King's College London, V. Sunil Babu Consultant in Psychiatry of Old Age, Director of Medica Education, Surrey and Borders Partnership Foundation NHS Trust, Oxted, OmanaThachil Consultant in Child and Adolescent Psychiatry, Sand well Mental Health and Social Care NHS Trust, West Bromwich, Furhan Iqbal Consultant Psychiatrist (General Adult and Community) South Rural Cambridge, Ranga Rao Consultant Psychiatrist, South London and Maudsley NHS FoundationTrust, Ladywell Unit, University Hospital Lewisham, London 